\title{
Pulmonary Function Studies of Conjoined Thoracopagus Twins
}

\author{
ROBERT E. BARROW, C. JOAN RICHARDSON, AND CHARLES E. APLIN II \\ University of Texas Medical Branch, Galveston, Texas, USA
}

\section{Summary}

Lung functions were measured on 13-day-old conjoined thoracopagus twins. Mean values for tidal volume and minute ventilation were $14.8 \mathrm{ml}$ and $1102 \mathrm{ml} / \mathrm{min}$ for twin $A$ and $12.8 \mathrm{ml}$ and $963 \mathrm{ml} /$ min for twin B. Functional residual capacities (FRC) were $35 \mathrm{ml} /$ $\mathrm{kg}$ and $39 \mathrm{ml} / \mathrm{kg}$ for twins $A$ and $B$, respectively. Pulmonary compliance and flow resistance for twin $A$ were $2.8 \mathrm{ml} / \mathrm{cm} \mathrm{H}_{2} \mathrm{O}$ and $75 \mathrm{~cm} \mathrm{H} \mathrm{H}_{2} \mathrm{O} / \mathrm{liter} \cdot \mathrm{sec}^{-1}$ with $45 \%$ of the total work used to overcome elastic resistance. Although values for resistance and work of breathing are within the normal range for studies reported elsewhere, these results tend to be elevated and probably reflect an abnormal state.

\section{Speculation}

With decreasing reluctance by surgeons to separate conjoined thoracopagus twins, data concerning their preoperative respiratory pathophysiology assumes greater importance. Pulmonary function tests on conjoined twins may provide valuable information concerning the feasibility and prognosis for successful separation.

Conjoined twins are a rare phenomenon. In humans, the incidence is estimated at 1 in 33,000-165,000 births. The most common type of conjoined twins is the thoracopagus. The authors recently had the opportunity to investigate ventilation and respiratory mechanics in female thoracopagus twins undergoing clinical evaluation to determine the feasibility of separation.

Many anatomic and physiologic characteristics of thoracopagus twins have been described $(1,10,12,15,18,19)$. Conjoined hearts and complex cardiovascular malformations have often precluded successful separation. Respiratory failure and pulmonary complications in the postoperative period have been considered secondary to large anterior defects of the diaphragm and abdominal and chest walls leading to paradoxical movement and ineffective ventilation. Other than pulmonary isomerism, the lungs of thoracopagus twins have been normal anatomically and to our knowledge, studies on the mechanics of breathing have not previously been reported.

\section{CASE REPORT}

Conjoined female thoracopagus twins were born after 35 weeks of gestation at the University of Texas Medical Branch, Galveston, Texas. The twins, joined from the suprasternal notch to the umbilicus, shared pericardium, diaphragm, and liver. Their combined weight was $4.3 \mathrm{~kg}$. Although both twins were $41.5 \mathrm{~cm}$ in length, twin $A$ appeared heavier. Twin $A$ had a normal cardiovascular system; however, twin B had severe cyanotic heart disease (double outlet right ventricle). Pulmonary functions were studied 13 days after birth. On that date, the infants were in satisfactory condition, breathing spontaneously, and resting on a radiant warmer (Ohio Medical Products, Madison; WI 53701). Their combined weight at this time was no different than birth weight.

\section{MATERIALS AND METHODS}

Flow rates were measured with Fleisch $\# 000$ pneumotachographs (Godart/Statham, Holland, Jan Van, Eycklaam 2, Bilthoven) adapted to infant anesthesia masks and connected to Statham PM283TC pressure transducers (Statham. Inc., 2230 Statham Blvd., Oxnard, CA 93030). Dead space volume of the pneumotachograph-mask assembly was $10 \mathrm{ml}$. Tidal volumes were obtained by electrical integration of the rate of flow signal from the pressure transducers. Intraesophageal pressure changes, as an index of intrapleural pressure changes (8), were measured with 1.6 $\mathrm{mm}$ outside diameter pressure transducer tipped catheters with a response time of less than $10 \mu \mathrm{sec}$ (Millar Instruments, Inc., P O Box 18227, Houston, TX). Pressure catheters were passed through airtight seals in the face masks and then nasally into the esophagus. Catheters were calibrated in $\mathrm{cm} \mathrm{H}_{2} \mathrm{O}$ by immersion in water containing a small amount of detergent. In this study, pressure changes and not absolute pressures were monitored. Elastic and flow resistances were calculated from simultaneous volume, rates of flow and intraesophageal pressure changes recorded on an 8 channel Brush 481 strip chart recorder (Gould, Inc., Brush Division, 3621 Perkins Ave., Cleveland, $\mathrm{OH}$ 14l14). Several minutes of adaptation to handling and tactile stimulation were necessary to calm the twins before recording data. Using a noninvasive technique (3), respiratory rates were monitored before and after this study to establish near basal breathing patterns.

FRC was measured by nitrogen wash out. The technique basically consists of replacing air breathing with $100 \%$ oxygen and using the volume of nitrogen washed out in calculating FRC ( 7 , 9 ). A nonbreathing valve system (2) adapted to an infant anesthesia mask permitted the infant to breathe from a gas bag partially filled with $100 \%$ oxygen and exhale into a collecting bag. After the infant breathed $100 \%$ oxygen for $2 \mathrm{~min}$, the exhaled gas volume was determined and the average nitrogen concentration measured with a Medical Gas Analyzer, type MGA-1100 (PerkinElmer, 2771 North Garey Ave., Pomona, CA 91767). Standard corrections for apparatus nitrogen volume, temperature, and water vapor were made.

Pulmonary compliance, calculated as the ratio of tidal volume to the corresponding change in intraesophageal pressure at points of zero flow, was expressed in $\mathrm{ml} / \mathrm{cm} \mathrm{H}_{2} \mathrm{O}$. Specific compliance was expressed as compliance/ml of FRC. Resistance to flow, calculated as the ratio of change in intraesophageal pressure minus face mask pressure to the corresponding total flow rate change at inspiratory and expiratory isovolumetric points, was expressed in $\mathrm{cm} \mathrm{H}_{2} \mathrm{O} /$ liter $\cdot \mathrm{sec}^{-1}$.

Work required for inspiration was calculated from a modified form of the equation used by Otis et al. (14). When expiration is assumed passive, the equation provides a method for estimating total positive mechanical work performed on the lungs per unit time. A simplified form of this expression, which assumes second order resistive factors negligible, was used by Cook et al. (5) to measure newborn infant lung mechanics. Work of breathing was calculated by substituting lung compliance, tidal volume, frequency of breathing, and flow resistance into the equation: 


$$
\dot{W}=0.5(C)^{-1} f\left(V_{T}\right)^{2}+0.25 K\left(\pi f V_{T}\right)^{2}
$$

Where: $\dot{\mathrm{W}}=$ work of breathing, $\mathrm{g} \cdot \mathrm{cm} / \mathrm{min} ; C=$ pulmonary compliance, $\mathrm{ml} / \mathrm{cm} \mathrm{H}_{2} \mathrm{O} ; f=$ frequency, breaths $/ \mathrm{min} ; V_{T}=$ tidal volume, $\mathrm{ml}$; and $K=$ flow resistance, $\mathrm{cm} \mathrm{H}_{2} \mathrm{O} / \mathrm{ml} / \mathrm{min}$. Percent elastic work was expressed as the ratio of the elastic resistance to the total work.

\section{RESULTS}

Tidal volume and minute ventilation for both infants are listed in Table 1. These data represent a total of 81 representative breaths from twin A and 58 representative breaths from twin B. Typical tracings of intraesophageal pressure changes, volume changes, and rates of flow during twin B's breath holding and during periods of quiet synchronous and asynchronous breathing are shown in Figures 1-3. The mean tidal volume for twin $A$ was $14.8 \mathrm{ml}$ (range, $7.5-25.5 \mathrm{ml}$ ) with a minute volume of $1102 \mathrm{ml} /$ min. Twin B had a mean tidal volume of $12.8 \mathrm{ml}$ (range, $8.0-16.5$ $\mathrm{ml}$ ) with an average minute volume of $963 \mathrm{ml} / \mathrm{min}$. Respiratory
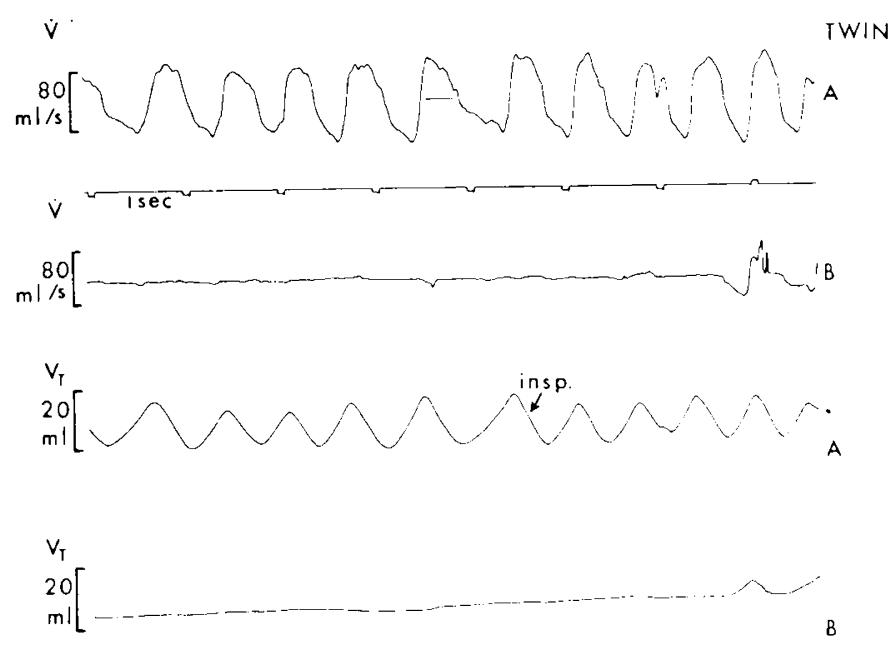

B
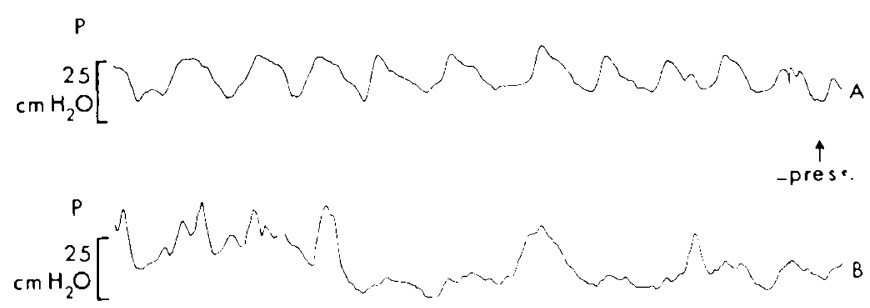

Fig. 1. Simultaneously recorded flow rates $\dot{V}(t o p)$, tidal volumes $V_{\mathrm{T}}$ (middle), and intraesophageal pressure changes (bottom). Twin B's breath holding. rates ranged from $68-95$ breaths/min for twin $\mathrm{A}$ and $50-87$ breaths/min for twin B.

Calculations on mechanics of breathing for twin $A$ are presented in Table 1. The mean lung compliance was $2.8 \mathrm{ml} / \mathrm{cm} \mathrm{H}_{2} \mathrm{O}$ (SD of a series of $60= \pm 1.3 \mathrm{ml} / \mathrm{cm} \mathrm{H}_{2} \mathrm{O}$ ) and ranged from 1.1-7.4 $\mathrm{ml} / \mathrm{cm} \mathrm{H}_{2} \mathrm{O}$. Lung resistance for twin A was $73 \mathrm{~cm} \mathrm{H}_{2} \mathrm{O} /$ liter. $\mathrm{sec}^{-1}$, and ranged from $21-163 \mathrm{~cm} \mathrm{H} \mathrm{H}_{2} \mathrm{O} / \mathrm{liter} \cdot \mathrm{sec}^{-1}$. The average work on the lungs was $7405 \mathrm{~g} \cdot \mathrm{cm} / \mathrm{min}$ with $45 \%$ of total work used to overcome elastic resistance. Valid data from twin B were insufficient for compliance, resistance and work of breathing calculations. Average FRC's were $75 \mathrm{ml}(\mathrm{SD} \pm 7 \mathrm{ml})$ for twin A and $84 \mathrm{ml}(\mathrm{SD} \pm 6 \mathrm{ml})$ for twin $\mathrm{B}$.

\section{DISCUSSION}

In this study, the infants were not considered basal due to handling and face mask stimulation. Breathing rates measured with a modified nontactile respirometer (3), however, showed no
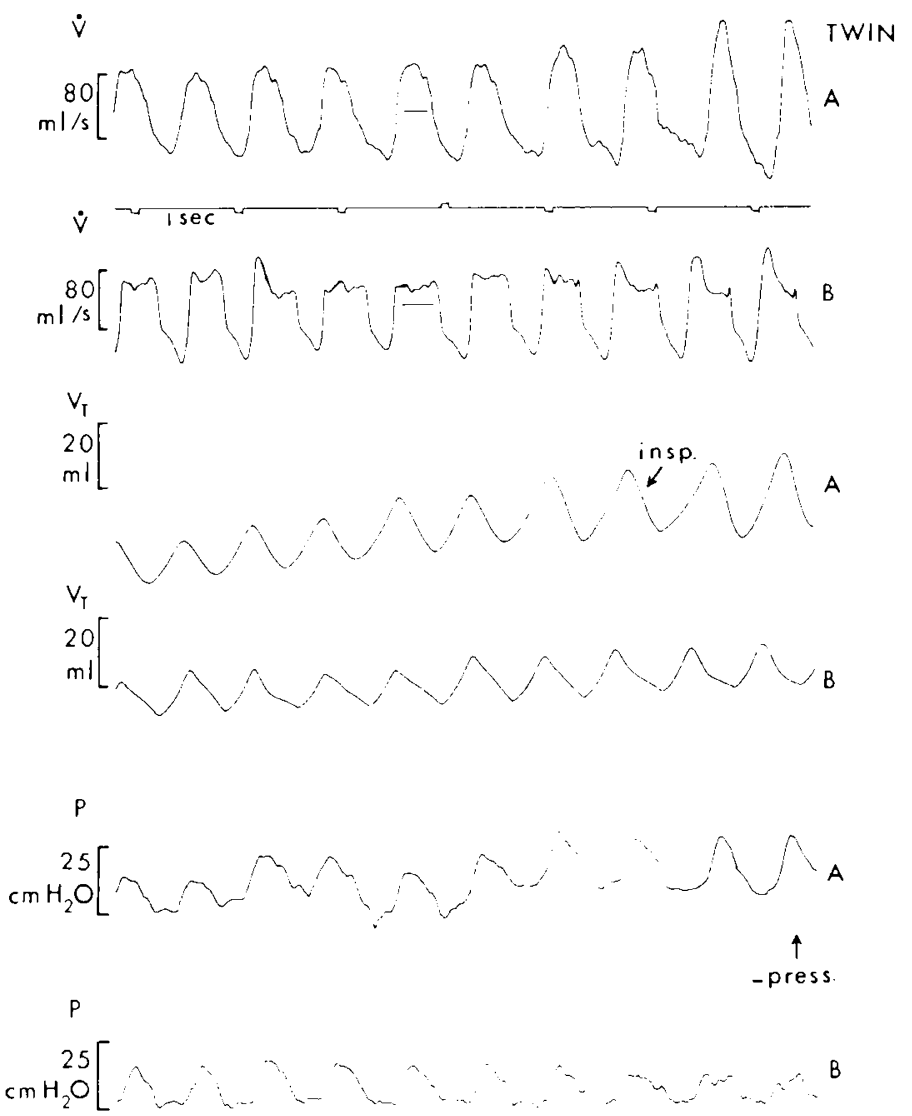

Fig. 2. Synchronous breathing; defined in this study as a breathing pattern in which end inspirations are separated by less than 0.1 sec.

Table 1. Lung function and respiratory mechanics in 13-day-old conjoined twins

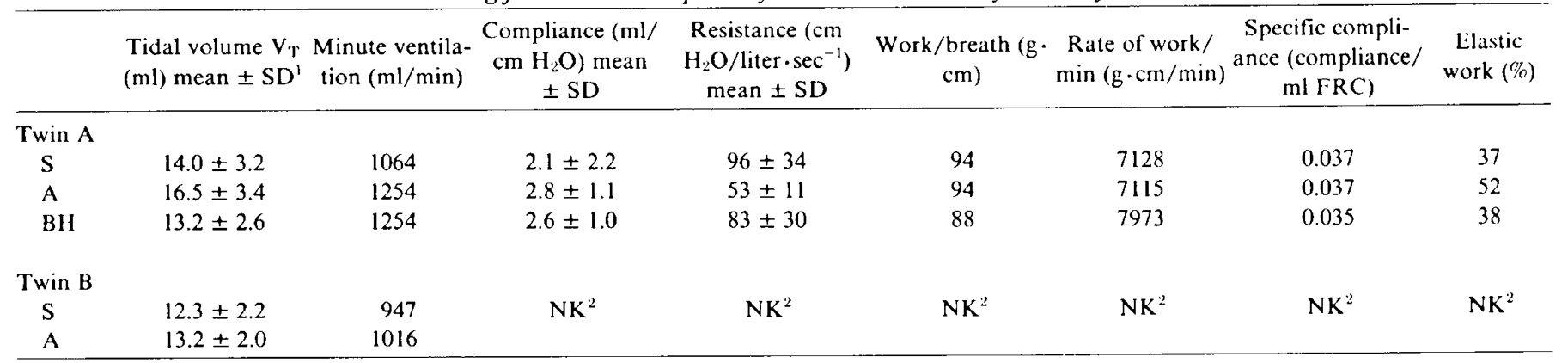

' $\mathrm{S}=$ synchronous breathing, $\mathrm{A}=$ asynchronous breathing, $\mathrm{BH}=$ during twin $\mathrm{B}$ breath holding.

${ }^{2} \mathrm{NK}=$ insufficient data. 
Table 2. Comparison of ventilatory mechanics in conjoined twins and normal infants ${ }^{1}$

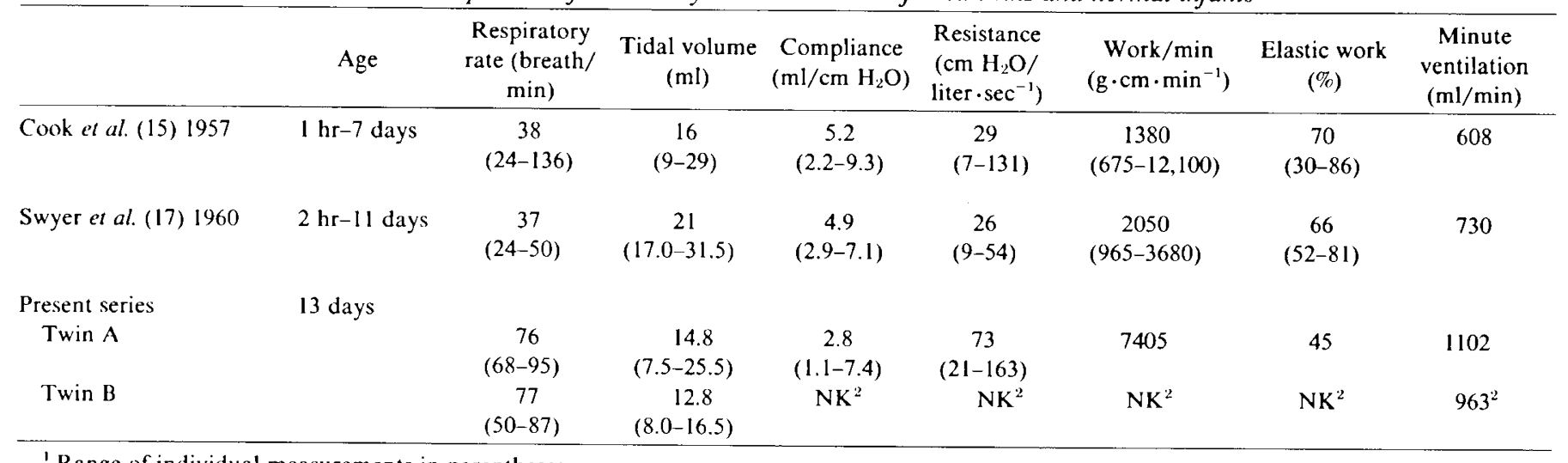

' Range of individual measurements in parentheses.

${ }^{2} \mathrm{NK}=$ insufficient data.

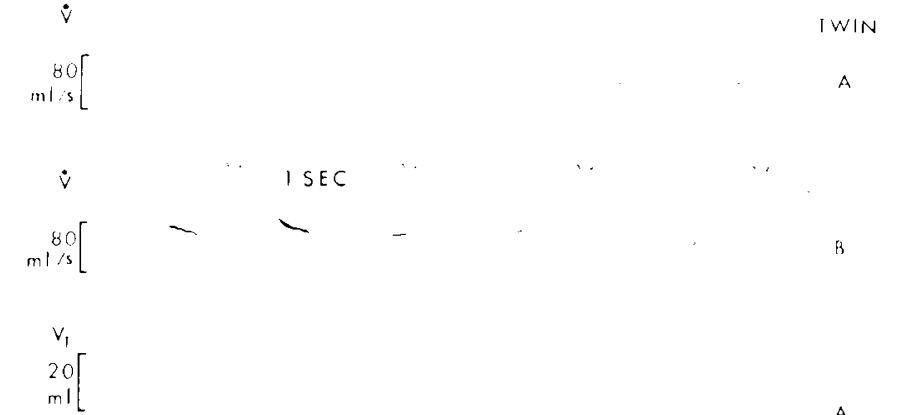

$$
\begin{aligned}
& v_{1} \\
& 20 \\
& \mathrm{ml}
\end{aligned}
$$

\section{insp}

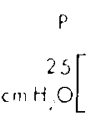

Fig. 3. Asynchronous breathing.

significant difference when compared with rates measured with face masks firmly held in place. While Cross et al. (6) have shown that resting state ventilation may not be reached until the infant has been asleep for $1 \mathrm{hr}$ or more, the authors believe the data presented represent an alert but quiescent state. Breathing rates reported by others (Table 2) on normal infants, however, are significantly lower than observed in this study. The higher rates observed may be a result of the anatomic nature of the common rib cage, sibling restriction, abnormalities in the mechanical efficiency of respiratory muscles, or anticipation of tactile stimulation.

The lungs and connecting airways are often compared to mechanical analog systems where force required to move air into the system equals the sum of the elastic elements plus flow resistive and inertial components. In applying the data from this study to approximating mechanical work of breathing, second order flow resistance factors were assumed negligible. Flow resistance pressure changes were measured at points of equal inspiratory and expiratory volumes (isovolumetric), which in effect averages in- spiratory and expiratory flow resistances. These points were selected near zero flow acceleration to minimize inertial components.

Intraesophageal pressures were assumed to represent the average transpulmonary pressure for the entire lung. In general, pressure changes appeared valid for twin $\mathrm{A}$, and compliance calculations from data recorded during twin B's apnea were not significantly different from data collected during synchronous or asynchronous breathing patterns. During simultaneous breathing, however, pressures monitored in twin $B$ were not a reliable measure of transpulmonary pressure-changes, but included changed corresponding to the breathing pattern of twin A (Figs. 2 and 3 ). Thus, due to the unusual anatomic arrangement, pressure waveforms from twin $B$ were difficult to analyze and insufficient data were collected to make valid calculations on lung mechanics.

Transpulmonary pressure changes were observed during periodic apnea in twin B (Fig. 1). Improper location of the pressure probe or periodic glottis closure could account for this phenomenon, however, no upper airway obstruction was observed in twin A or B. Clinically, apnea did not present a problem in twin B. No fluoroscopic studies were made to locate the exact position of the pressure probes in relationship to the other.

FRC volumes based on body weight were $35 \mathrm{ml} / \mathrm{kg}$ and $39 \mathrm{ml} /$ $\mathrm{kg}$ for twin $\mathrm{A}$ and twin $\mathrm{B}$, respectively, and are comparable to volumes previously reported $(4,11,16)$. Based upon investigations of normal infants $(9,11,13)$, it was assumed that changes in FRC were minimal and the distribution of inspired gas was normal. While care was taken in keeping the face masks in place, small leaks would lead to an overestimation of the FRC volume.

This study was limited to function and mechanics of the lungs and not directed at the chest wall and respiratory muscle abnormalities. Restrictions imposed by the chest wall could influence normal lung function, i.e., increased respiratory rate and decreased tidal volume. During the short period of time required for data recording, no significant change in respiratory rate or tidal volume was observed and thus, it was concluded that minute ventilation and work of breathing were not seriously compromised by apparatus dead space ventilation.

It is noteworthy that many functions measured were within the range of normal values reported (Table 2). For diagnostic purposes, however, it was difficult to compare data from this study to the average values for infants of different ages as shown in Table 2 . The presumed etiology of any abnormalities, however, appear related to the chest wall and not the lungs.

The twins were successfully separated at 5 wk of age. Both twins had large anterior chest wall defects and required positive pressure ventilation for several weeks postoperatively. Twin B died at 7 months of age due to severe cyanotic heart disease (double outlet right ventricle with pulmonary artery atresia). Anatomically, her lungs were normal. Twin A at 24 months of age is normal with no evidence of respiratory disease. 


\section{REFERENCES AND NOTES}

1. Bankole, M. A., Oduntan, S. A., Oluwasaumi, J. O., Itayeni, S. O., and Khwaja, S.: The conjoined twins of Warri, Nigeria. Arch. Surg., 104: 294 (1972).

2. Barrow, R. E.: Nonrebreathing valve system for small animal respiratory measurements. J. Appl. Physiol., 40: 108 (1976).

3. Barrow, R. E., Colgan, R. F.: A noninvasive method for measuring newborn respiration. Respir. Care, 18: 412 (1973).

4. Berglund, G., and Karlberg, P.: Determination of the functional residual capacity in newborn infants, Acta Paediatr., 45: 541 (1956).

5. Cook, C. D., Sutherland, J. M., Segal, S., Cherry, R. B., Mean, J., Mcllroy, M. B., and Smith, C. A.: Studies of respiratory physiology. III. Measurements of mechanics of respiration. J. Clin. Invest., 36: 440 (1957).

6. Cross, K. W., Hooper, J. M. D., and Oppé, T. E.: The effect of inhalation of carbon dioxide in air on the respiration of the full term and premature infant J. Physiol., 122: 264 (1953).

7. Darling, R. C., Cournand, A., and Richards, D. W., Jr.: Studies on the intrapulmonary mixture of gases. III. An open circuit method for measuring residual air. J. Clin. Invest., 19: 609 (1940)

8. Dinwiddie, R., and Russell, G.: Relationship of intraesophageal pressure to intrapleural pressure in the newborn. J. Appl. Physiol., 33: 415 (1972).

9. Hanson, J. S., and Shinozaki, T.: Hybrid computer studies of ventilatory distribution and lung volume. I. Normal Newborn infants. Pediatrics, 46: $900(1970)$

10. Hill, A. J., Peterson, C. G., Grondahl, R. D., Kreppachne, W. W.: Conjoined thoracopagus twins. J. Pediatr., 59: 59 (1961).

I1. Klaus, M., Tooley, W. H., Weaver, K. H., and Clements, J. A.: Lung volume in the newborn infant. Pediatrics, 30: 111 (1962).

12. Marrone. A. A.: Thoracopagus Twins, Obstet. Gynecol., 4: 658 (1954).

13. Nelson, N. M.. Prod'hom, L. S., Cherry, R. B., Lipsitz, P. J., and Smith, C. A.: Pulmonary function in the newborn infant: The alveolar-arterial oxygen gradient. J. Appl. Physiol., I8: 534 (1963).
14. Otis, A. B., Fenn, W. O., and Rahn, H.: The mechanics of breathing in man. J. Appl. Physiol. 2: 592 (1950).

15. Singer, D. B., and Rosenberg, H. S.: Pathologic studies of thoracopagus conjoined twins, Birth Defects Original Article Series, New York, The National Foundation March of Dimes, 3: 97 (1967).

16. Strang L. B., and McGrath, M. W. Alveolar ventilation in normal newborn infants studied by air wash-in after oxygen breathing. Clin. Sci., 23: 129 (1962).

17. Swyer, P. R., Reiman, R. C., and Wright, J. J.: Ventilation and ventilatory mechanics in the newborn. J. Pediatr., 56: 612 (1960).

18. Vallbona, C., and Hazelwood, C. F.: Physiologic monitoring of conjoined twins: objectives and clinical usefulness, Birth Defects Original Article Series, New York, The National Foundation March of Dimes, 3: 106 (1967).

19. Zimmermann, A. A.: Embryologic and anatomic considerations of conjoined twins, Birth Defects Original Article Series, New York, The National Foundation March of Dimes, 3: 18 (1967).

20. Informed consent was obtained from the parents for all diagnostic procedures during the twins' entire stay in John Sealy Hospital, University of Texas Medical Branch. Galveston, TX.

21. The authors thank the medical staff of the Intensive Care Nurseries at University of Texas Medical Branch, Galveston, TX, for their cooperation in providing assistance and information throughout this study.

22. Dr. Barrow is Assistant Professor, Department of Physiology and Biophysics.

23. Dr. Richardson is Associate Professor and Director. Division of Perinatal Pediatrics, Department of Pediatrics.

24. Dr. Alpin is Senior Fellow, Division of Perinatal Pediatrics.

25. This research was supported by the National Foundation March of Dimes grant 6-17.

26. Requests for reprints should be addressed to: Dr. C. Joan Richardson. Department of Pediatrics. University of Texas Medical Branch, Galveston, TX 77550, USA.

27. Received for publication May 8, 1978.

28. Accepted for publication August 10, 1978 